\title{
Coping Mechanism/Resources of Young and Old Widows in South West Nigeria
}

\author{
Dr. Falana Bernard Akinlabi \\ Department of Guidance and Counselling \\ Faculty of Education, Ekiti State University, Nigeria. \\ Tel: 08033944390, E mail - falana2010@yahoo.com
}

Doi:10.5901/mjss.2013.v4n2p193

\begin{abstract}
The study investigated the differences that existed between young and old widows and their ammenability to coping mechanism and resources. The researcher made use of descriptive research design of the survey type. All the widows in South West Nigeria were surveyed. A self-designed instrument titled 'Young and Old Vulnerable Widows Questionnaire' (YOVWQ) was administered on randomly selected widows. A sample of one hundred young and old widows were randomly selected using multistage sampling technique involving stratified and purposive sampling techniques. The instruments validity was ensured facially, contentwise and constructwise by subjecting it to relevant experts. A reliability co-efficient of 0.78 was obtained from Pearson Product Moment Correlation Analysis using test retest reliability method. Copies of the instrument was personally administered by the researcher and trained research assistants in the various locations of the respondents. The data generated were analysed using appropriate descriptive and inferential statistics. The analysis of the data revealed that respondents (old and young) widows did not differ in their coping strategies and mechanisms.Based on the findings curriculum planner should incorporate into the national curriculum areas to be taught to students that will change orientation and reduce agonies of mourning widows. Also the culture of Will writing should be incorporated to couples life to alleviate the agonies of widows. The study could be of benefit to students, teachers, curriculum planners, widows, widowers, counsellors, professional care givers and teaming religious leaders in Nigeria.
\end{abstract}

Keywords: Young, old, widows, coping mechanisms, coping resources, bereavement, mourning, grief.

\section{Introduction}

Loss in human life is unavoidable and it is ubiquitous, loss could be incurred in terms of disappointment, finance, fire, drought, flood, accident and in many ways. The most irreparable loss human being can have is death. The most dangerous loss one can incure is the loss of a loved one. It can be loss of a work mate, friend, brother, uncle, niece, nephew classmate, brother, child, sibling and so on. The conjugal loss appears to be one of the deadly loss one can ever experience. It is fatal, canal and perilous because it appears as if a branch is severed from the trunk. Whenever someone loses his or her spouse he or she is in a permanent or perpetual state of grief and bereavement. The situation of bereavement is worsened by the cultural dictates of the society. This is because bereavement is elongated by the cultural observations of people. Widows both old and young have their bereavement extended and debilitating as a result of cultures expressed in mourning expressed rituals about what to eat, where to sleep, days to stay indoor, cloths worn, ceremonies to attend, control over properties, ceremonies to attend, inheritance practices and caring for the living and non living properties of the deceased.

The researcher observed that there seems to be differences in the coping mechanisms of young widows and old widows in South West Nigeria. It appears as if the old widows that is widows that experience conjugal loss after 11 years of marriage appears to cope with bereavement than widows that incurred conjugal loss less than 10 years of that marriages. The widows generally experiences feelings of tension and stress. These are experienced in the forms of cognitive, dissonance and experienced of shame. Bereavement generally appears to be a state of discomfort. The bereaved are discomforted in handling various life issues in the absence of the deceased. Issues like, managing the material resources of the deceased, taking care of the children, managing the extended relatives especially in a typical complex Yoruba culture of South West Nigeria meeting the cultural dictates, thinking alone, actualising the uncompleted 
projects of the deceased, remarrying another spouse. All these posses a lot of challenges on the incapacitated bereaved.

In other to face all these arduous challenges the bereaved widows appears to result to coping mechanisms like adaptive mechanisms, that offers positive help, attack mechanisms, avoidance mechanisms, behavioural mechanisms, cognitive mechanisms, conversion mechanisms, defence mechanisms, self-harm mechanisms, crying, denial, compensation, displacement, dissociation, emotionality, fantasy help rejecting complaining, idealisation, identification, intellectualisation, introjection, passive aggression performing rituals, post traumatic growth projection, provocation, rationalization, reaction formation, regression, repression, self-harming somatization, sublimation, substitution suppression symbolization and trivializing undoing.

Coping actions or mechanisms for the widows are symptoms of deeper problems and addressing them directly can be ineffective or even counter-productive. The best approach is to discover the deeper cause of the problems which will ultimately result in coping mechanism disappearing. If one is using deliberate theatrical methods during persuasion, feigning a coping mechanism makes it harder for the other person to broach an apparently stressful situation for you.

Widowhood changes the social and economic roles of women both in the house and the society. It alters the structure of the family. The effect is severe and it is based majorly on religion and culture. It appears to affect the safety, identity, mobility of women and children, it affects their access to basic goods and services necessary for survival and their rights to inheritance of land and property. It impacts on the community because widowed women has lost recognition. It has psychological effect coupled with insecurity. They are deprived of support from the traditional sources which elongates the problem of economic hardship infact in most cases the widows appears to be vulnerable to intimidation, violence or abuse, or repudiation by the society. This have even resulted to widows grieving in silence in addition to raising a family. They are seen saying that their main reason for going on with in life is the responsibility of raising their dependent children. The children have their own share in the deprivation by subjecting them to discrimination and unfair treatment because of their mothers status.

In South West Nigeria, widows are responsible for her late husband's dependants if the late husband is the breadwinner of the extended relatives if the woman is of little or no educational background she can face additional difficulties as head of household and prevented from acquiring additional education. This can restrict her capacity to find work. In Nigeria culture where customary law restricts women to have the right to own land and property. This appears to make the widowed women to be homeless and unable to support themselves and their dependants and there appears to be inadequate social support for the widows in Nigeria.

Whenever women are bereaved, it impacts on emotional adjustment, role loss, related adjustments, social adjustment and financial adjustment.

The emotional adjustment depends on the length of marriage, this is because many couples have shared their youths, had children together and supported each other during many life transitions and family, crises, they have been friends, companions and sexual partners. This have serious emotional impact. Holmes \& Rahe (1967) observed that loss of a spouse is ranked as one of the most stressful of all potential life changes on life event scale. Older women engage on mental rehearsals of their own potential widowhood as they watch friends and relatives loose loved ones; they should survive their spouses. For young married person loss of a spouse is unanticipated and hardly is any preparation made for the eventuality, the young widow feels deserted, the thought of raising children alone becomes frightening. Anger and guilt is the lot of the young widow.

Moss \& Moss (1984) reported that elderly widow after many years of marriage continues to maintain a deep attachment to the deceased. This emotional tie persists through the grieving period and that it is potentially a significant and permanent theme in the elderly person's life.

Reorganisation of social roles is required. This is because widowhood is a very disorganising experience as a result of role loss. Lopata (1993) reported that the degree of disorganisation depends on the degree to which the deceased was an integral part of the mates life and self concept as well as the status of widow in the particular culture involved. Not only are additional responsibilities assumed after a spouse dies, but a major role is lost as well it becomes hazardous and debilitating for younger widowers than for elderly widows.

Clark, Siviski\& Weiner (1986) reported that loneliness is a major problem of widows and this is the greatest concern, this has resulted to social maladjustment. The widows assumes the role of maintaining social and kinship ties and organising social events. The younger the widow, the greater the chances of remarriage, it may be difficult for widow to meet single persons in their age group, dating seems to be very awkward after many years of marriage. Unlike men, there are social sanctions against women marrying men younger than themselves. 
Adolescents or adult children may interfere with the possibility of their widowed parent's remarriage by objecting to their deceased father being replaced and not accepting the surviving parents desire to seek adult companionship.

Financial adjustment is also a significant aspect of adjustment to widowhood. Handling finance for young and old widows during the period of emotional pain can be overwhelming, the younger the widow, the less experience and the less experience one has had in this area, the more painful and stressful it will likely be: acquiring financial knowledge can be an important way to help a spouse prepare for widowhood and gaining experience in financial decision making can reduce the anxieties associated with the task of widowhood.

The death of a spouse astronomically increases the risk of a drop in economic well-being for women both old and young. Burkhauser, Butler and Holden (1991) reported that widows are likely to enter poverty after spousal loss and experience a large income decline. Young widows compared with elderly women of today have acquired more formal education, have identified more strongly with a work role and have higher earning potential, they appears to have more experience with financial matters.

\section{Research Rationale}

The researcher observed that young and old widows in South West Nigeria appears to be in perpetual agony. The elongation and elasticity of their bereavement is dependant in their ability to exhibit emotional adjustment, role loss and related adjustment, social adjustment and financial adjustment. The researcher also observed that young and old widows in South West Nigeria are susceptible to varying coping mechanisms and resources. All these appears to be accountable for longevity of bereavement experienced in women widowhood. The researcher is therefore interested in finding out whether young and old widows amenability to these hoping resources/mechanisms enhances their respite during widowhood

\section{Methodology}

The study investigated the differences that existed between young and old widows and their susceptibility to coping resources. The study investigated whether the young and old widows in South West Nigeria differ in their exposure to different resources. The researcher employed the descriptive research design of the survey type. A sample of one hundred young and old widows were selected using simple multistage, stratified and purposive sampling techniques. A research instrument titled "Young and Old Vulnerable Widows Questionnaire" (YOVWQ) was self-designed by the researcher and used to collect data. The instruments face, content and construct validity was ensured by relevant experts. The instrument's test retest reliability was done and the coefficient was ensured and estimated at 0.78 using Pearson Product Moment Correlation Analysis and found significant at 0.05 level of significance. The data generated after administration of the instrument was analysed using descriptive and inferential statistics.

\section{Descriptive Analysis}

Research Question: What is the adjustment rate of young and old widows?

The widows are categorised based on their years of marriages at widowhood. Respondents below 10 years of marriage were categorised as young widows while widowed women who are 11 years and above were categorised as old widows.

Table 1 frequency counts percentages and adjustment rate of young and old widows.

\begin{tabular}{|c|c|c|c|c|c|c|c|c|c|c|c|c|c|c|c|c|c|}
\hline Widows & No & \multicolumn{4}{|c|}{ Emotional } & \multicolumn{4}{|c|}{ Social } & \multicolumn{4}{|c|}{ Financial } & \multicolumn{4}{|c|}{ Job Role } \\
\hline \multirow[b]{2}{*}{ Young } & \multirow[b]{2}{*}{50} & $P$ & $\%$ & $\mathbf{N}$ & $\%$ & $P$ & $\%$ & $\mathrm{~N}$ & $\%$ & $\mathbf{P}$ & $\%$ & $\mathrm{~N}$ & $\%$ & $\mathbf{P}$ & $\%$ & $\mathrm{~N}$ & $\%$ \\
\hline & & 21 & 42 & 29 & 58 & 19 & 38 & 31 & 62 & 27 & 54 & 23 & 46 & 26 & 52 & 24 & 48 \\
\hline Old & 50 & 32 & 64 & 18 & 36 & 28 & 56 & 22 & 44 & 29 & 58 & 21 & 42 & 34 & 68 & 16 & 32 \\
\hline Total & 100 & & & & & & & & & & & & & & & & \\
\hline
\end{tabular}


Table 1 above shows the frequency counts and percentage responses of young and old widows to adjustment by the respondents. There are indications in the table that the widows, 11 years and above appears to adjust to emotions, social, finance and job role than young widows who experienced widowhood less than 10 years of marriage.

Hypothesis Testing

Research Hypothesis:The young and old widows will not significantly adjust to identified adjustment factors.

Table 2: $\mathrm{t}$ - test analysis of young and old widows and adjustment to identified factors.

\begin{tabular}{|c|c|c|c|c|c|c|}
\hline Group & $\mathbf{N}$ & Mean & SD & Df & t-cal & t-table \\
\hline Young widows & 51 & 32.37 & 2.14 & & & \\
\cline { 1 - 4 } Old widows & 49 & 31.83 & 2.19 & 98 & 1.238 & 1.980 \\
\hline
\end{tabular}

$P>0.05$ (not Significant)

Table 2 shows that t-cal (1.238) is less than t-table (1.980) at 0.05 level of significance. The null hypothesis is accepted. This implies that years of marriage at widowhood will not influence adjustment to identified adjustment factors.

\section{Discussion}

The findings in table 2 showed that the young and old widows are not influenced by emotional, social, financial and job role. This finding contradicts Cook \&Oltenbruns (1998) who reported that older women engage in mental rehearsals of their own potential widowhood, they have plans in the event they should survive their spouses. Loss of spouses for young married persons is usually inanticipated.

The descriptive analysis revealed that it appears as if the older widows adjusted to resources (emotions, social, finance and job role) than young widows. This may be due to the fact that older widows have enough experiences, social networking and elongated or elastic coping mechanisms. The finding also supports Olaniyi (2011) who reported that there was a significant difference between young and old widows in the way they have conflict with their inlaws, she reported that younger widows frequently conflict more than old widows with their inlaws. The finding contradicts Falana (2010) who reported that there is no significant difference between young and old widows in their attitude to death related grief.

The discrepancies in the findings may be as a result of susceptibility of widows to different subcultures and their amenability to social networking, different coping resources and different job roles.

Moss \& Moss (1984) reported that elderly widows after many years of marriage continues to maintain a deep attachment to the deceased. The finding also negates Bound (1991) findings that a womens financial resources decreased by $18 \%$ following the death of a husband and widows on the average live 18.5 years after their husband's death also King (1985) reported that women with fewer economic resources at their disposal at earlier stages of their lives are the ones who must live longer on relatively less and less. The aging of the population makes the feminization of poverty a pervasive reality.

\section{Significance of the Study}

The study could be of benefit to the students, teachers, counsellors, curriculum planners, widows, widowers, professional care givers, prospective researchers and religious leaders. Students could learn the significance of length of marriage on bereavement process and coping mechanisms and resources to students and the impact of length of marriage of widows on bereavement and adjustment to grief. The curriculum planners could incorporate into the schools curriculum areas to be taught to students on bereavement and adjustment. Widows could go through their grieves with reduced agonies. It could serve as eye opener to prospective researchers and generate further researches. Health care practitioners could understand how and why of behaviours of bereaved widows and render appropriate assistance. 


\section{Recommendations}

Based on the findings it is therefore recommended that the areas of the culture that elongates tenacity of bereavement and grief should be removed. The sophisticated mass media in Nigeria should present programmes that should reduce the agonies of the young and old widows. The training of teachers should be such that they will teach student's on ways to empathise with messages that will alleviate the agonies of the bereaved widows. The curriculum planners should incorporate into the national curriculum areas to be taught that will benefit widows, widowers, counsellors and health care practitioners.

\section{References}

Bound, J. (1991): Poverty dynamics in widowhood. Journal of Gerontology, 46 (3), S115 - S124.

Burkhauser, R.V., Butler, J.S. \& Holden, K.G. (1991)|: How the death of a spouse affects economic well-being after retirement: A hazard model approach. Social Science Quarterly, 72 (3), $504-519$.

Clark, P.G. Siviski, R.W. \& Weiner, R. (1988): Coping strategies of widowers in the first year. Family relations 35 (3), $425-430$

Cook, A.S. \&Oltjenbruns, K.A. (1998): Dying and Grieving life span and family perspectives, Harcourt Brace \& Company.

Falana, B. A (2010) Attitudes to Death Related Grief Among the Yoruba People of Nigeria. Unpublished Ph.D Thesis, University of Ado-Ekiti, Ekiti State, Nigeria.

Lopata H.Z. (1993): The support systems of American urban widows. In M.S. Stroebe, W. Stroebe\& R.O. Hanson (Eds) Handbook of bereavement (pp205 - 211) Dubuque, I.A. William C. Bown.

Moss, M.S. \& Moss, S.Z. (1984): Some aspects of the elderly widow(er)'s persistent with the deceased spouse. Omega, 15 (3), $195-206$.

Olaniyi, C. M. (2011) Problems of Widowhood Practices among Nigeria Widows. Unpublished Ph.D Thesis, University of AdoEkiti, Ekiti State, Nigeria.

Holmes, T.H. \&Rahe, R. (1967): Social readjustment rating scale Journal of Psychometric Research, 11, 213 - 218. 
